\title{
FOXM1 overexpression is associated with cisplatin resistance in non-small cell lung cancer and mediates sensitivity to cisplatin in A549 cells via the $\mathrm{JNK} / \mathrm{mitochondrial} \mathrm{pathway}$
}

\author{
Y. LIU๋, X. CHEN", Y. GU, L. ZHU, Y. QIAN, D. PEI, W. ZHANG*, Y. SHU*
}

${ }^{1}$ Department of Oncology, First Affiliated Hospital of Nanjing Medical University, Nanjing 210029, P.R.C; ${ }^{2}$ Department of Gastroenterology, First Affiliated Hospital of Nanjing Medical University, Nanjing 210029, P.R.C

*Correspondence: yongqianshucn@126.com, zhangweifengc@163.com

${ }^{*}$ Contributed equally to this work.

Received November 22, 2013 / Accepted June 27, 2014

\begin{abstract}
The Forkhead box M1 transcription factor (FoxM1) is essential for DNA replication and mitosis, and has important role in cell proliferation and apoptosis. To assess the role of FoxM1 in chemoresistance, we investigated FoxM1 protein expression and the correlation between FoxM1 expression, sensitivity to cisplatin-based therapy, and the survival of non-small cell lung cancer (NSCLC) patients. We generated a cisplatin-resistant lung cancer cell line (A549/CDDP) that showed elevated expression levels of FoxM1 protein and mRNA relative to those of the parental A549 cells. We investigated the effect of the knockdown or overexpression of FoxM1 on the sensitivity to cisplatin and the possible signaling transduction pathways in these cells. Our results revealed that the positive expression rate of FoxM1 in NSCLC was associated with chemosensitivity to cisplatin and a poor prognosis. When the expression of FoxM1 was inhibited by RNA interference, the sensitivity to cisplatin was enhanced. Inversely, in FoxM1-overexpressing cell models, we observed a reduced sensitivity to cisplatin. Moreover, we showed that the downregulation of FoxM1 enhanced cisplatin-induced A549/CDDP cell apoptosis through the activation of the c-Jun NH2-terminal kinase (JNK)/mitochondrial pathway. These results suggest that FoxM1 plays a critical role in chemoresistance to cisplatin and that FoxM1 depletion may be a promising approach to lung cancer therapy.
\end{abstract}

Key words: FoxM1, cisplatin, drug resistance, non-small cell lung cancer, A549, JNK/mitochondrial pathway

Lung cancer is one of the most common malignancies worldwide, and is the leading cause of cancer-related death [1]. Non-small cell lung cancer (NSCLC) is the most common type of lung cancer, accounting for $80-85 \%$ of all lung cancer cases [2]. Approximately $70 \%$ of NSCLCs are in an advanced stage at the time of diagnosis [3] and, consequently, the 5-year survival across stages is only $15 \%$. Systemic chemotherapy is still the main life-prolonging and palliative treatment in advanced NSCLC, and cis-diamminedichloroplatinum (CDDP, cisplatin) is the backbone of first-line chemotherapy doublets. However, both acquired and intrinsic resistances remain a major hurdle that has limited the treatment success. The mechanisms of cisplatin resistance involve multiple pathways, including the evasion of apoptotic pathways, a bypass of the replication checkpoint, increased cell proliferation, and increased DNA damage repair $[4,5]$, which are not fully understood. Therefore, further elucidating the biological mechanisms of cisplatin resistance and the key molecules and pathways that regulate this resistance is necessary to overcome treatment plateaus in NSCLC.
Forkhead box M1 (FoxM1), which belongs to the Forkhead transcription factor family, is essential for DNA replication and mitosis, and has important roles in cell proliferation and apoptosis $[6,7]$. The expression of FoxM1 is enhanced in the G1/S and G2/M phases and can mediate cells in the $S$ and $M$ phases $[8,9]$. The knockout of FoxM1 causes failure to enter the $S$ phase and improper $M$ phase completion in cells, which leads to centrosome amplification and mitotic catastrophe [10, 11]. The upregulation of FoxM1 expression is closely associated with the occurrence, development, and prognosis of various human cancers such as pancreatic cancer and lung cancer [1214]. Furthermore, FoxM1 expression level correlates positively with tumor size, clinical stage, metastasis, and survival in breast cancer and colon carcinoma $[15,16]$.

In addition to being a cell cycle transcription factor, recent studies have confirmed that FoxM1 is involved in DNA damage and apoptosis pathways, which suggests that FoxM1 plays a role in multidrug resistance [17-20]. FoxM1 stimulates the transcription of the X-ray repair cross-complementing group 1 (XRCC1) [21] and the breast cancer-associated 
gene 2 (BRCA2), which are involved in the homologous recombination repair of DNA double-strand breaks [22-24]. FoxM1-deficient(-/-) mouse embryonic fibroblasts (MEFs) and osteosarcoma U2OS cells exhibit DNA breaks, increased transcriptional activation of the p53 tumor suppressor, and increased mRNA and protein levels of the p53 downstream target $\mathrm{p} 21^{\text {cip } 1}$ [25]. Furthermore, an increased expression of FoxM1 and its downstream targets, which are involved in DNA repair and apoptosis, has been observed in cisplatin-resistant breast cancer cell line (MCF-7-CIS ${ }^{\mathrm{R}}$ ). Silencing FoxM1 expression caused breast cancer cells to become more sensitive to doxorubicin by regulating DNA repair genes [26]. In addition, FoxM1 mediates the resistance to herceptin and paclitaxel by regulating the tubulin-destabilizing protein stathmin in breast cancer cells [27]. Attenuated FoxM1 expression restored the sensitivity to gefitinib in lung cancer cells by inhibiting proliferation and inducing apoptosis [28]. These results suggest a novel role for FoxM1 in the transcriptional response to DNA damage signaling and the induction of apoptosis, and a potential target for reversing chemoresistance.

In our study, we first investigated FoxM1 protein expression levels and the correlation between FoxM1 expression, sensitivity to cisplatin-based therapy, and the survival of NSCLC patients. Then, we investigated the effect of FoxM1 knockdown or overexpression on human NSCLC cell sensitivity to cisplatin and the possible mechanism for this sensitivity.

\section{Patients and methods}

Patients and clinical specimens. In this study, we examined samples from 50 patients with histopathologically confirmed primary NSCLC without radical surgery at our hospital from 2004-2008. All patients were untreated. The first-line treatment was a cisplatin-based regimen for at least 2 cycles. The efficacy of chemotherapy was evaluated by spiral computed tomography (CT) after 2-4 cycles. All patients clinical and pathological data were integrated.

Immunohistochemical analysis. FoxM1 protein accumulation was examined by immunohistochemical (IHC) staining. Sections from paraffin-embedded tumors were incubated with a sheep anti-human FoxM1 monoclonal antibody (R\&D Systems; Littleton, CO, USA) at a 1:2000 dilution for $3 \mathrm{~h}$, followed by washing with phosphate-buffered saline (PBS) and incubation with a goat anti-sheep secondary antibody (Thermo Fisher Scientific, Inc.; Rockford, IL, USA). Antigen-antibody complexes were visualized by incubation with $3^{\prime}, 3$-diaminobenzidine $(\mathrm{DAB})$ substrate and counterstained with diluted Harris hematoxylin. A negative control was run simultaneously using the primary antibody. Normal human lung tissue was used as a positive control.

Immunohistochemical staining of FoxM1 in the tissue was scored by pathologists blinded to the clinicopathological parameters, by applying a modification of the semi-quantitative immunoreactivity score (IRS) in the training cohort, as reported elsewhere. Category A documented the intensity of immunostaining as $0-3(0$, no immunostaining; 1 , weak immunostaining; 2, moderate immunostaining; 3 , strong immunostaining). Category B documented the percentage of immunoreactive cells as $0(<1 \%), 1(1-10 \%), 2(11-50 \%)$, and 4 (51-100\%). Multiplication of category A and B resulted in an IRS ranging from 0 to 12 for each tumor. A resulting score of $>4$ was considered positive, whereas a score of $0-3$ was considered negative.

Cell culture and chemotherapeutic agents. A549 (human lung adenocarcinoma) cells were obtained from the American Type Culture Collection (Manassas, VA, USA) and grown in RPMI 1640 (HyClone; Logan, UT, USA), which was supplemented with $10 \%$ fetal bovine serum, 100 units $/ \mathrm{mL}$ penicillin, and $100 \mathrm{~g} / \mathrm{mL}$ streptomycin in a $37^{\circ} \mathrm{C} \mathrm{CO}_{2}$ incubator. The cells were selected by stepwise exposure to increasing CDDP concentrations up to $5 \mathrm{Ag} / \mathrm{mL} \mathrm{L}$. The cells were then maintained for at least 6 months in medium that contained 5 Ag/mL CDDP. The CDDP-resistant cells (A549/CDDP) were cultured without CDDP for 2 weeks before analysis. CDDP was purchased from Sigma (St Louis, MO, USA), dissolved in dimethyl sulfoxide and stored at $-20^{\circ} \mathrm{C}$.

Cytotoxicity analysis. The cells were plated in 96-well plates and incubated for an additional $24 \mathrm{~h}$. The cells were treated with various concentrations $(0,5,10,20,40$, and $80 \mu \mathrm{mol} / \mathrm{L})$ of cisplatin. After $48 \mathrm{~h}$ of incubation, $10 \mu \mathrm{L}$ of Cell Counting Kit-8 (CCK-8) was added, and the culture was continued for $3 \mathrm{~h}$ in a humidified atmosphere that contained $5 \% \mathrm{CO}_{2}$. Absorbance was measured at $450 \mathrm{~nm}$ using a microplate reader (Bio-Tech; VT, USA). The relative drug resistance fold-changes were determined according to the $50 \%$ inhibitory concentration (IC50).

Real-time quantitative polymerase chain reaction (PCR). For real-time PCR, total RNA was extracted from tissues and sorted cells using the RNeasy Mini Kit (Qiagen; Hilden, Germany). A complementary DNA synthesis was performed using SuperScript Reverse Transcriptase (RT) II (Invitrogen; Carlsbad, CA, USA) and a mixture of oligo (dT). SYBR Green-based real-time PCR was conducted with FastStart Universal SYBR Green (ROX) reagents and an ABI PRISM 7300 Genetic Analyzer (Applied Biosystems; Foster City, CA, USA). The cycling program was $95^{\circ} \mathrm{C}$ for $20 \mathrm{~min}$, followed by 40 cycles of $95^{\circ} \mathrm{C}$ for $15 \mathrm{~s}$ and $60^{\circ} \mathrm{C}$ for $1 \mathrm{~min}$. Each sample was assayed in triplicate and the results were normalized to the level of the ribosomal protein L19 RNA. The forward and reverse primers were as follows: FOXM1-F, 5' -TGCAGCTAGGGATGTGAATCTTC-3', FOXM1-R, 3'-GGAGCCCAGTCCATCAGAACT-5'; L19-F, 5' -GCGGAGAGGGTACAGCCAAT-3', L-19-R, 3'-GCAGCCGGCGCAAA-5'.

Western blotting. The cells were collected and washed with PBS before incubation in radioimmunoprecipitation assay buffer that contained $1 \%$ Nonidet P-40, $50 \mathrm{mM}$ Tris- $\mathrm{HCl}(\mathrm{pH}$ 7.4), $1 \mathrm{mM}$ ethylenediaminetetraacetic acid, $150 \mathrm{mM} \mathrm{NaCl}$, and the addition of a complete protease inhibitor mixture. The cells were lysed on ice for $20 \mathrm{~min}$ and spun down to remove 
cell debris. The protein concentration of the lysates was determined using a Bio-Rad protein assay (BioRad, Laboratories Inc; Hercules, CA, USA). The lysates were diluted in $5 \times$ sodium dodecyl sulfate (SDS) loading buffer, boiled for $5 \mathrm{~min}$, separated on SDS-polyacrylamide gel electrophoresis gels and transferred to nitrocellulose membranes, which were probed with antibodies (anti-FoxM1 antibody was purchased from R\&D Systems; Minneapolis, MN, USA; anti-Bcl-2, -Bax, -p- cJun NH2-terminal kinase (JNK), -JNK, - $\beta$-actin, and -GAPDH were purchased from Cell Signaling Technology, Inc.; Danvers, MA, USA), visualized using an ECL reagent, and detected and analyzed using the Bio-Rad Gel Doc XR System.

Transfection of small interfering RNA (siRNA). siRNA that was directed against human FoxM1 (FoxM1-siRNA) and a non-targeting negative control siRNA (NC-siRNA) were purchased from Dharmacon (Denver, CO, USA). The target sequences of the selected siRNA oligonucleotides were as follows: P1, 5'-CCAACAAUGCUAAUAUUCA-3 '; P2, 5 '-CAUUGGACCAGGUGUUUAA-3 '; 3 , 5 '-GCGCACGGCGGAAGAUGAA-3'; and 4, 5 ' -UGAAAGACAUCUAUACGUG-3'. A549/CDDP cells were plated into the wells of a 6 -well plate at $1.0 \times 10^{6}$ cells per well in $2 \mathrm{~mL}$ of $10 \%$ fetal bovine serum-supplemented Dulbecco's modified Eagle medium on the day before transfection. After 24 h of incubation, A549/CDDP cells were transfected with FoxM1-siRNA or NC-siRNA duplexes. The transfection procedures were performed following the FuGENE HD transfection reagent manufacturer's protocol (Roche Applied Science; Indianapolis, MN, USA). After $12 \mathrm{~h}$, the transfection efficiency was determined using fluorescence

Table 1. The relationship between clinicopathological factors and FoxM1 protein expression

\begin{tabular}{|c|c|c|c|}
\hline & \multicolumn{2}{|c|}{ FoxM1 } & \multirow[t]{2}{*}{$P$ value } \\
\hline & Positive $(n=22)$ & Negative $(n=28)$ & \\
\hline Sex & & & 0.907 \\
\hline Male & 13 & 17 & \\
\hline Female & 9 & 11 & \\
\hline Age & & & 0.403 \\
\hline$\geq 60$ & 6 & 10 & \\
\hline$<60$ & 16 & 18 & \\
\hline Histological type & & & 0.947 \\
\hline Ad & 14 & 17 & \\
\hline Scc & 4 & 6 & \\
\hline Others & 4 & 5 & \\
\hline TNM stage & & & 0.71 \\
\hline IIIA & 2 & 1 & \\
\hline IIIB & 4 & 5 & \\
\hline IV & 16 & 22 & \\
\hline Degree of differentiation & & & 0.392 \\
\hline Poor & 12 & 11 & \\
\hline Moderate /well & 10 & 17 & \\
\hline
\end{tabular}

Ad: Adenocarcinoma; Scc: Squamous cell carcinoma microscopy of A549/CDDP cells that were transfected with FAM-labeled negative control siRNA duplexes. The silencing effect was assayed by quantitative real-time PCR and western blot analysis, $2 \mathrm{~d}$ post-transfection.

Construction and transfection of the eukaryotic expression vector FoxM1b-pcDNA3.1 (+). The overexpression plasmids and dominant-negative FoxM1 (a loss-of-function mutant of FoxM1; negative control) were purchased from Generay Company (Shanghai, China). The transfected cells were seeded to a confluency of 50\% and incubated for $6 \mathrm{~h}$ with a mastermix of transfection reagents that contained Fugene-6 (Qiagen; Hilden, Germany) and the plasmids, which were diluted at a ratio of 3:1 in Opti-MEM. Fresh medium was added to replace the transfection reagent, and the cells were allowed to grow overnight. The transfection effect was assayed by quantitative real-time PCR and western blot analysis, 2 d post-transfection.

Statistical analysis. The data are expressed as the mean \pm standard deviation (SD). A statistical analysis was performed

Table 2. First-line and subsequent treatment in FoxM1 protein-positive and -negative groups

\begin{tabular}{lccc}
\hline & \multicolumn{2}{c}{ FoxM1 } & \multirow{2}{*}{ p value } \\
\cline { 2 - 3 } & Positive (n=22) & Negative (n=28) & \\
\hline First-line treatment & 12 & 16 & 0.86 \\
Gemcitabine/CDDP & 5 & 8 & \\
Paclitaxel/CDDP & 2 & 2 & \multirow{2}{*}{0.89} \\
Vinorelbine/CDDP & 3 & 2 & \\
Docetaxel/CDDP & & & \\
Subsequent treatment & 3 & 2 & \\
Erlotinib & 4 & 6 & \\
Gefitinib & 4 & 5 & \\
Other chemotherapy & & & \\
\hline
\end{tabular}

Table 3. Treatment responses to cisplatin-based therapy in unresectable NSCLC

\begin{tabular}{lcc}
\hline Treatment response & Number of patients & Percentage(\%) \\
\hline CR & $0 / 50$ & 0 \\
PR & $17 / 50$ & 34 \\
SD & $16 / 50$ & 32 \\
PD & $17 / 50$ & 34 \\
CR+PR+SD & $33 / 50$ & 66 \\
\hline
\end{tabular}

Table 4. The relationship between FoxM1 protein expression and treatment responses

\begin{tabular}{lccl}
\hline \multirow{2}{*}{ Treatment response } & \multicolumn{2}{c}{ FoxM1 } & \multirow{2}{*}{$\boldsymbol{p}$ value } \\
\cline { 2 - 3 } & Positive $(\mathbf{n}=\mathbf{2 2})$ & Negative $(\mathbf{n}=\mathbf{2 8})$ & \\
\hline $\mathrm{CR}+\mathrm{PR}+\mathrm{SD}$ & 9 & 24 & 0.002 \\
$\mathrm{PD}$ & 13 & 4 & \\
\hline
\end{tabular}




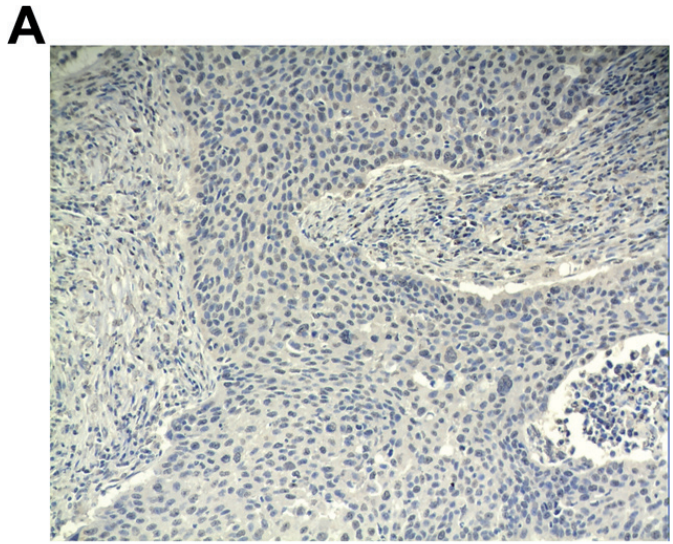

B
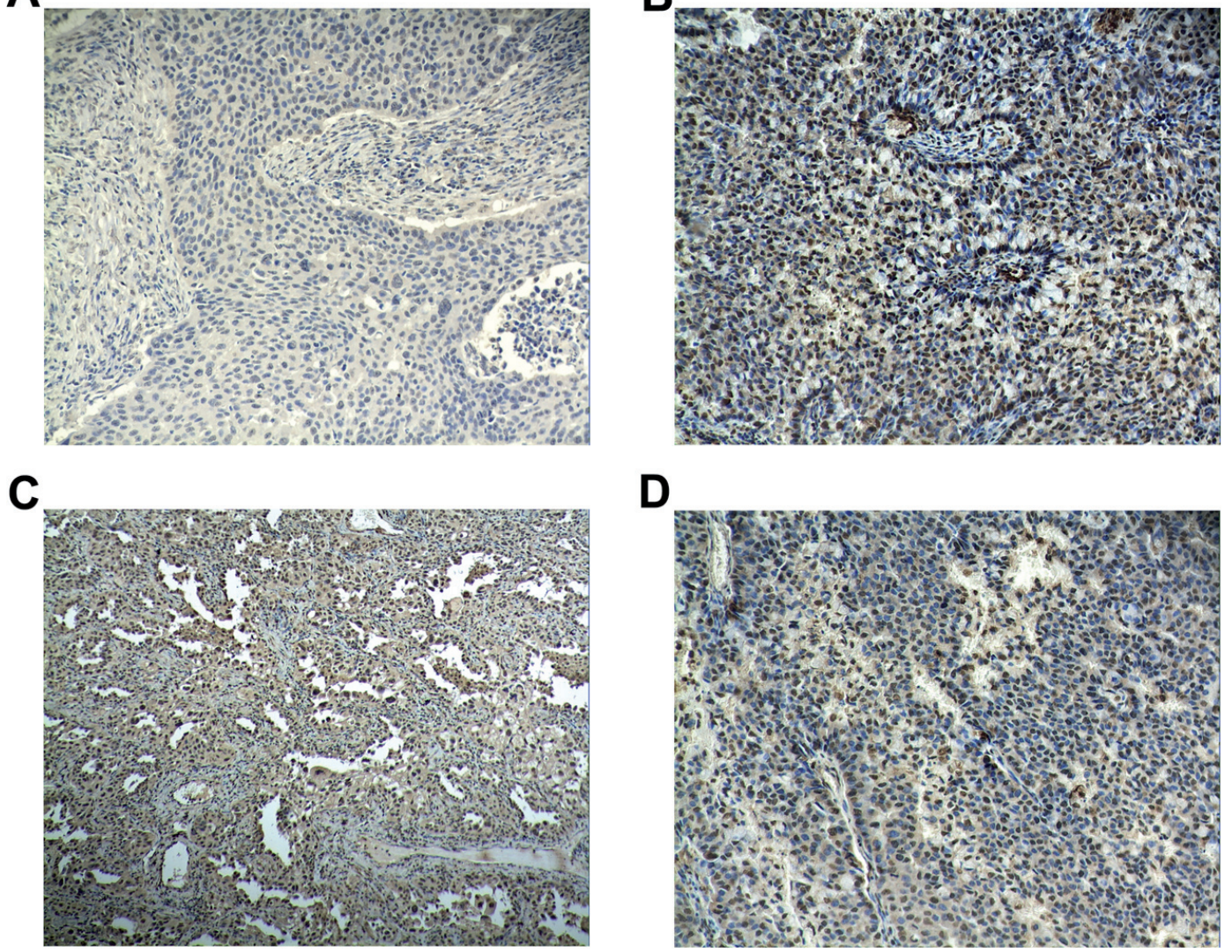

D

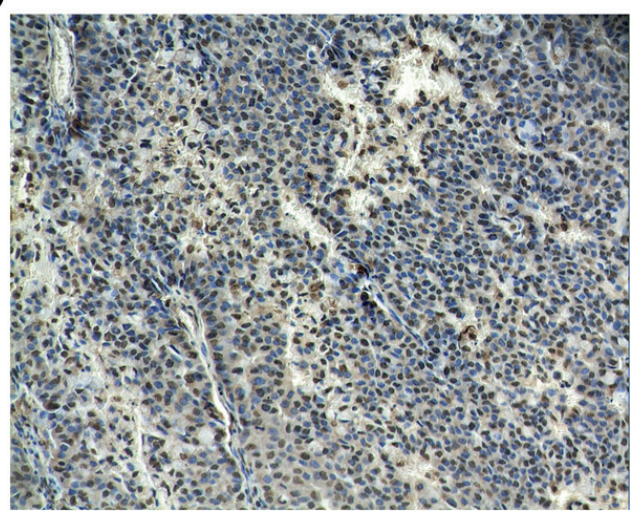

Figure 1. FoxM1 expression in NSCLC by immunohistochemistry.

A) Negative FoxM1 expression (200× magnification). B) Positive FoxM1 expression ( $200 \times$ magnification). C) Positive FoxM1 expression in differentiated lung cancer $(200 \times$ magnification). D) Positive FoxM1 expression in undifferentiated lung cancer $(200 \times$ magnification $)$.

using SPSS (Statistical Package for the Social Sciences) software (Release 17.0, SPSS, Inc.; Chicago, IL, USA). Associations between FoxM1 expression and clinicopathological characteristics (Table 1) or therapy lines (Table 2) were analyzed using the $\chi^{2}$ test. The relationships between FoxM1 protein expression and treatment responses (Table 4) were also analyzed using the $\chi^{2}$ test. Survival probability analyses were performed using the Kaplan-Meier method. The significance of the group differences was assessed by the log-rank test. Multivariate analyses were performed using a logistic regression model for response and Cox regression models for progression-free survival (PFS) and overall survival (OS). The differences between the two groups were analyzed by the Student's $t$-test or one-way analysis of variance (ANOVA). A value of $P<0.05$ was considered to be statistically significant.

\section{Results}

FoxM1 expression in advanced NSCLC patients correlated with response to cisplatin-based chemotherapy and survival. We investigated the expression of FoxM1 in
50 unresectable stage III-IV NSCLC tissue samples using an immunohistochemical assay. The cohort included 20 female patients and 30 male patients who were $36-79$ years of age (median age $=55$ years). The mean follow-up period after diagnosis was 25.0 months. The specimens originated from percutaneous lung biopsy (21 cases), transbronchial lung biopsy (11 cases), lymph node biopsy (13 cases), and palliative surgery ( 5 cases). The histological classification was based on the 2004 World Health Organization criteria. No chemotherapy or radiotherapy was given to the patients before biopsy.

FoxM1 staining was mainly located in the nucleus. Of the patients who were treated with a cisplatin-based regimen as first-line therapy, $56.0 \%(28 / 50)$ had a tumor with low FoxM1 expression (Fig. 1A), whereas the remaining patients exhibited high FoxM1 expression (Fig. 1B), which included both differentiated (Fig. 1C) and undifferentiated (Fig. 1D) lung tumor samples. The correlation between the immunohistochemical staining patterns and the clinical and pathological factors was examined (Table 1). The results indicated that there was no significant difference between FoxM1 levels and sex, age, 

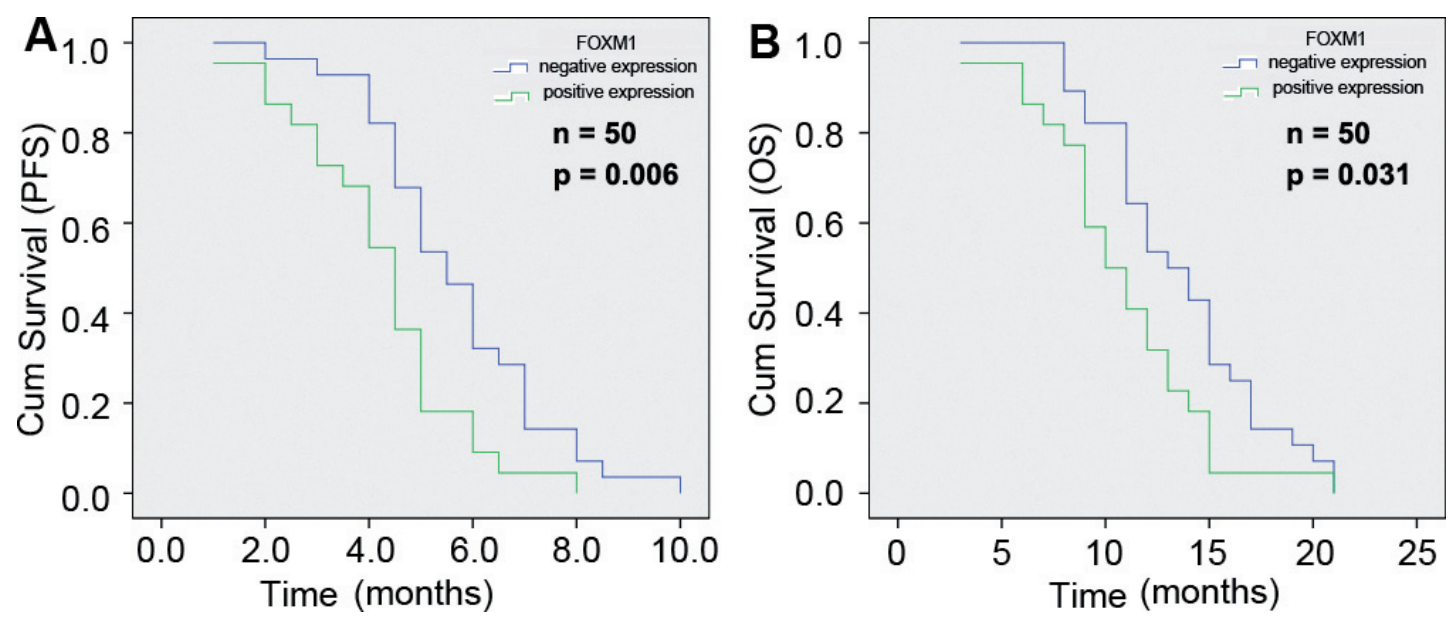

Figure 2. The Kaplan-Meier curve of PFS (A) and OS (B) of NSCLC patients with positive and negative FoxM1 immunohistochemistry staining. The log-rank test was used to test the two survival distributions.

histological type, degree of differentiation, and clinical stage $(P>0.05)$. Table 2 shows a summary of the first-line treatments and the use of erlotinib or gefitinib as a subsequent treatment. Gemcitabine-cisplatin was the most commonly selected firstline therapy. The high and low FoxM1 expression groups did not vary significantly according to the first-line regimens and the use of tyrosine kinase inhibitors. The epidermal growth factor receptor status was not assessed.

The disease control rate (DCR) after cisplatin-based therapy for all patients was $66.0 \%$ (17 partial responses, 16 patients presented a stable disease, and 17 patients presented a progressive disease, Table 3). The patients with a low expression of FoxM1

Table 5. Univariate analysis of the clinicopathological factors, FoxM1 protein expression and $\mathrm{OS}$

\begin{tabular}{lccc}
\hline Factors & $\begin{array}{c}\text { Number of } \\
\text { patients }\end{array}$ & OS (month) & p value \\
\hline Sex & 30 & $12(9.853-14.147)$ & 0.759 \\
$\quad$ Male & 20 & $11(9.748-12.252)$ & \\
$\quad$ Female & & & \\
Age & 16 & $13(11.040-14.960)$ & 0.488 \\
$\quad \geq 60$ & 34 & $11(9.574-12.426)$ & \\
$\quad<60$ & 3 & & 0.039 \\
TNM stage & 9 & $15(12.316-17.684)$ & \\
$\quad$ IIIA & 38 & $11(9.983-12.017)$ & \\
IIIB & & & 0.430 \\
IV & 33 & $12(10.068-13.932)$ & \\
Degree of differentiation & 16 & $12(10.569-13.431)$ & \\
$\quad$ Poor & & & \\
$\quad$ Moderate / well & 22 & $10(7.702-12.298)$ & 0.031 \\
FoxM1 protein expression & 28 & $13(10.407-15.593)$ & \\
Positive & &
\end{tabular}

had a higher DCR $(24 / 28,85.7 \%)$ than the patients from the high-expression group $(9 / 22,40.9 \%)(P=0.002$, Table 4$)$.

The overall PFS was 5.0 months (range $=1.0-10.0$ months), and the OS was 12.0 months (range $=3.0-21.0$ months). The PFS for patients with a low expression of FoxM1 was 5.5 months compared with 4.5 months for patients with a high expression of FoxM1 ( $P=0.006$, Fig. 2A). In addition, a better OS was observed in patients with a low expression of FoxM1 $(P=0.031$, Fig. 2B). The univariate analysis indicated that tumor stage and FoxM1 protein expression were important factors that affected OS (Table 5). These parameters were prognostic factors for OS in the multivariate analysis using the Cox regression model (Table 6).

FoxM1 expression in cisplatin-resistant A549 cells. To verify the role of FoxM1 in cisplatin resistance, we investigated the difference between the expression of FoxM1 in A549 and A549/CDDP cells. We established cisplatin-resistant A549/ CDDP cells from A549 human lung cancer cells by stepwise exposure to increasing concentrations of cisplatin. As shown in Figure 3A, the IC50 concentration of A549/CDDP cells was 9.33-fold higher than that of A549 cells $(135.21 \mu \mathrm{mol} / \mathrm{L}$ versus $14.49 \mu \mathrm{mol} / \mathrm{L}$ ) when the cells were treated with cisplatin. Subsequent real-time quantitative PCR revealed that the FoxM1

Table 6. Independent prognostic value of clinical variables and FoxM1 in relation to the overall survival by Cox multivariate analysis

\begin{tabular}{lccc}
\hline Covariate & Risk ratio & $\begin{array}{c}\text { 95\% confidence } \\
\text { interval }\end{array}$ & p value \\
\hline Sex & 1.208 & $0.638-2.288$ & 0.561 \\
Age & 1.396 & $0.711-2.743$ & 0.333 \\
TNM stage & 1.798 & $1.117-2.893$ & 0.016 \\
Degree of differentiation & 0.846 & $0.410-1.747$ & 0.651 \\
FoxM1 protein expression & 2.471 & $1.236-4.941$ & 0.010 \\
\hline
\end{tabular}


A
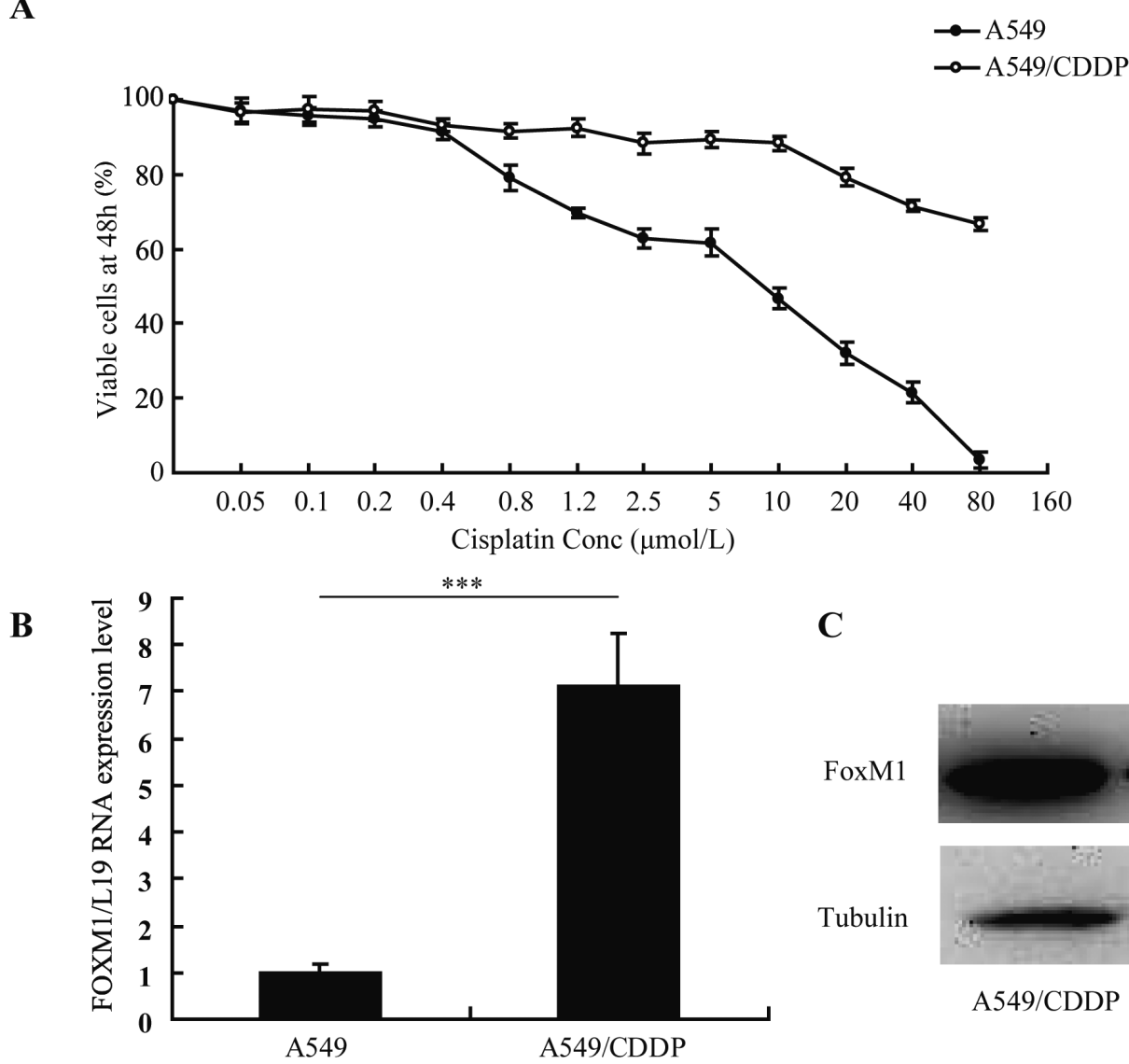

C

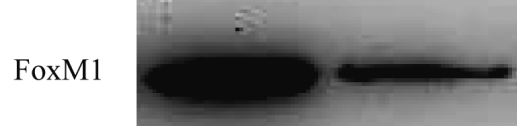

Tubulin

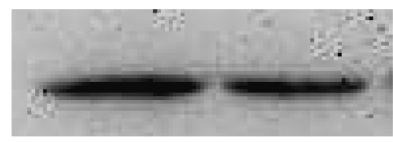

A549/CDDP A549

Figure 3. The cisplatin-resistant cell line (A549/CDDP) reveals elevated FoxM1 protein and mRNA expression levels.

A) A549 and A549/CDDP cells were exposed to increasing concentrations of cisplatin, stepwise, and the rates of cell proliferation were measured using the CCK-8 $(P<0.001)$. B C $)$ A549/CDDP cells were treated at $5 \mathrm{Ag} / \mathrm{mL}$ of cisplatin, and A549 cells were not treated with cisplatin. FoxM1 gene expression was determined at mRNA levels $\left(B,{ }^{* *} P<0.001\right)$ and by Western blotting $(C)$, respectively.

mRNA level was on average 7.1-fold higher in A549/CDDP cells compared with parental A549 cells (Fig. 3B). The results of the western blot analysis were in accordance with those of the real-time quantitative PCR (Fig. 3C).

Downregulation of FoxM1 by RNA interference sensitizes cisplatin-resistant A549 cells to apoptosis induced by cisplatin. In this study, the RNA interference technique was employed to knockdown FoxM1 expression in A549/CDDP cells. As shown in Figure 4A, the transfection efficiency of A549/CDDP cells that were transfected with FAM-labeled negative control siRNA duplexes was more than $80 \%$, as determined by fluorescence microscopy. The expression of FoxM1 mRNA and protein was significantly more suppressed in A549/CDDP-FoxM1-siRNA cells than in A549/ CDDP-NC-siRNA or A549 non-transfected cells according to the real-time quantitative PCR and western blot results (Fig. 4B, C), which suggested that RNA interference could effectively inhibit FoxM1 expression in A549/CDDP cells. A cytotoxicity analysis using CCK-8 was performed to detect cell proliferation in the presence of various concentrations of cisplatin. The results demonstrated the sensitivity of A549/ CDDP-FoxM1-siRNA cells to the cisplatin treatment with a $76.4 \%$ decrease in the IC50 compared with that of control cells (Fig. 4D).

Overexpression of FoxM1 using the eukaryotic expression vector FoxM1b-pcDNA3.1(+) decreased the sensitivity of A549 cells to cisplatin. To determine whether FoxM1 is important in cisplatin resistance, we constructed the eukaryotic expression vector FoxM1b-pcDNA3.1(+) and transfected the vector into A549 cells. The real-time quantitative PCR and western blot results showed that the expression of FoxM1 mRNA and protein was significantly more elevated in FoxM1b-pcDNA3.1(+)-A549 cells than in dominantnegative A549 cells or in A549 non-transfected cells (Fig. $5 \mathrm{~A}, \mathrm{~B})$, which suggested that transfection of the eukaryotic expression vector FoxM1b-pcDNA3.1(+) could effectively increase FoxM1 expression in A549 cells. The proliferation rates were evaluated using CCK- 8 and showed that the IC50 in the FoxM1b-pcDNA3.1(+)-A549 cells increased 313\% more than in the control groups (Fig. $5 \mathrm{C}$ ), which suggested 
A
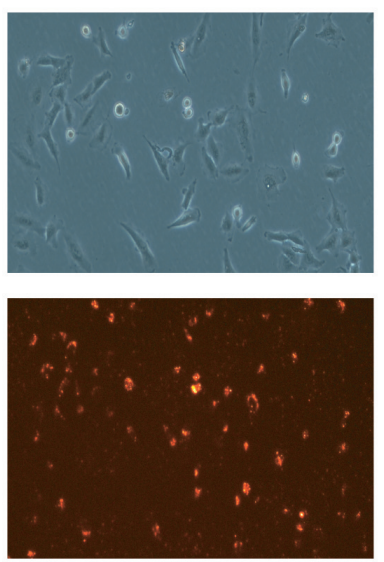

C

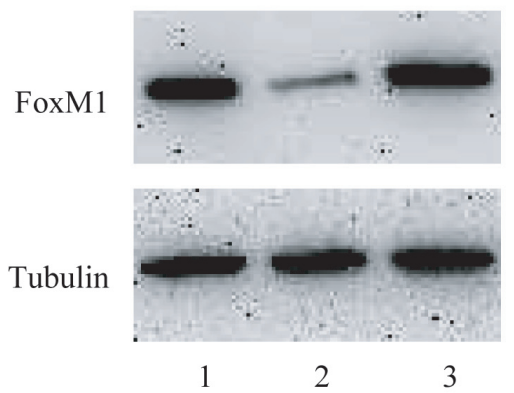

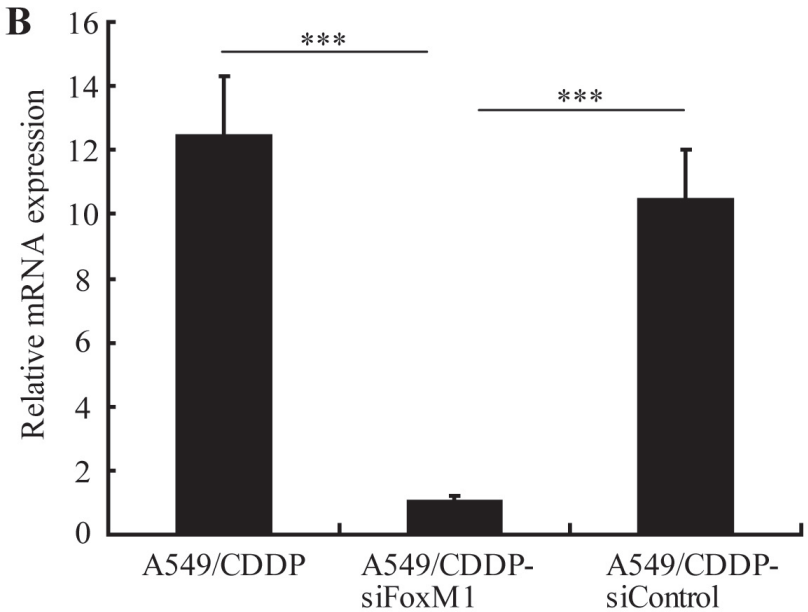

D

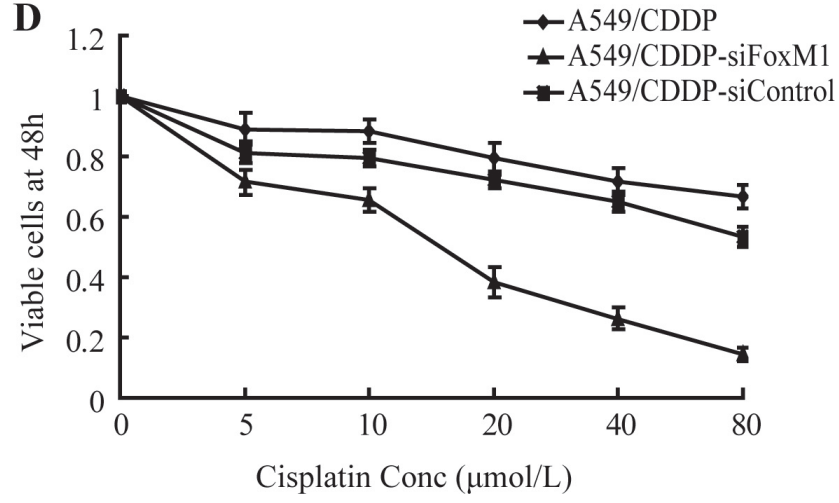

Figure 4. Downregulation of FoxM1 by RNAi-sensitised cisplatin-resistant A549 cells led to apoptosis induced by cisplatin.

A) The transfection efficiency of A549/CDDP cells that were transfected with FAM-labelled negative control siRNA duplexes was determined using fluorescence microscopy. B, C) The effects of FoxM1-siRNA on FoxM1 mRNA and the FoxM1 protein were assessed using real-time PCR ( $* * *<<001$ ) and western blot. D) The effects of various concentrations $(0,5,10,20$, and $40 \mu \mathrm{mol} / \mathrm{L})$ of cisplatin on the three types of cells over $24 \mathrm{~h}$ were assessed using the CCK-8 ( $P<0.001$ versus A549/CDDP-nontransfection cells or A549/CDDP-siControl cells). 1, A549/CDDP-nontransfection; 2, A549/CDDPsiFoxM1; 3, A549/CDDP-siControl. Statistical analysis was done using ANOVA analysis.

that the overexpression of FoxM1 decreased the sensitivity of A549 cells to cisplatin.

Downregulation of FoxM1 enhanced cisplatin-induced A549/CDDP cell apoptosis through upregulation of JNK phosphorylated level. We hypothesized that the mitochondrial pathway could be involved in the cisplatin-induced A549/ CDDP-FoxM1-siRNA cell apoptosis. To test this hypothesis, three types of cells (non-transfected A549/CDDP, A549/ CDDP-FoxM1-siRNA, and A549/CDDP-NC-siRNA) were treated with cisplatin $(20 \mu \mathrm{mol} / \mathrm{L})$ or cisplatin $(20 \mu \mathrm{mol} / \mathrm{L})$ combined with SP600125 $(10 \mu \mathrm{mol} / \mathrm{L})$, a specific inhibitor of JNKs, for $12 \mathrm{~h}$. Next, the cell viability was analyzed using CCK8 assays. JNK, p-JNK, Bcl-2, and Bax were further assessed by western blot analysis. The results (Fig. 6) revealed that JNK was significantly phosphorylated in the A549/CDDP-FoxM1siRNA cells that were treated with cisplatin. In addition, the expression of $\mathrm{Bcl}-2$ was reduced, whereas the expression of $\mathrm{Bax}$ was enhanced and accompanied by increased cell apoptosis. When SP600125 was used, the western blot demonstrated that the activation of JNK and the apoptosis pathway were inhibited, and cisplatin-induced apoptosis in A549/CDDPFoxM1-siRNA cells decreased.

\section{Discussion}

Cisplatin is widely used for the treatment of non-small cell lung cancer. However, chemoresistance remains a major therapeutic problem. The precise molecular mechanisms of cisplatin resistance are not fully understood. Based on our data, low expression rate of FoxM1 in NSCLC was associated with increased chemosensitivity to cisplatin. There was a significant negative relationship between high expression of FoxM1 and survival time. Cox multivariate analysis demonstrated that FoxM1 expression was an independent factor of poor prognosis. When the expression level of FoxM1 was downregulated and upregulated, sensitivity to cisplatin was respectively enhanced and reduced in both A549 and A549/ CDDP cells. FoxM1 downregulation enhanced cisplatin- 

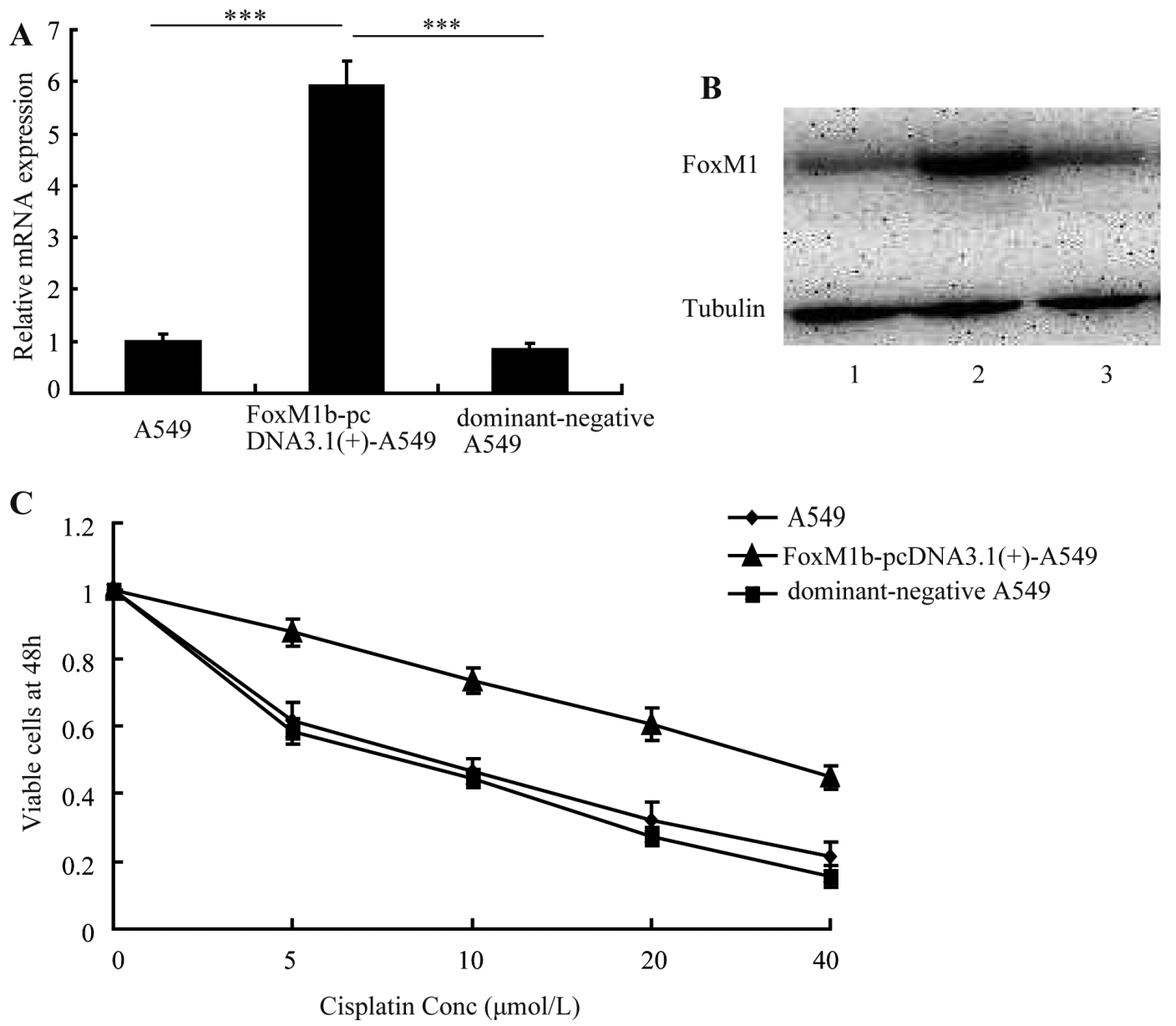

Figure 5. Upregulation of FoxM1 by the eukaryotic expression vector FoxM1b-pcDNA3.1(+) decreased the sensitivity of the A549 cells to cisplatin. A, B) The transfection efficiency of FoxM1b-pcDNA3.1(+) was assessed using real-time PCR and western blotting in the three types of cells. C) The effects of various concentrations $(0,5,10,20$, and $40 \mu \mathrm{mol} / \mathrm{L})$ of cisplatin on the three types of cells over $24 \mathrm{~h}$ were assessed using the CCK-8 $\left({ }^{\star} P<0.01\right.$ vs. A549-nontransfection cells or dominant-negative A549 cells). Statistical analysis was done using ANOVA analysis.

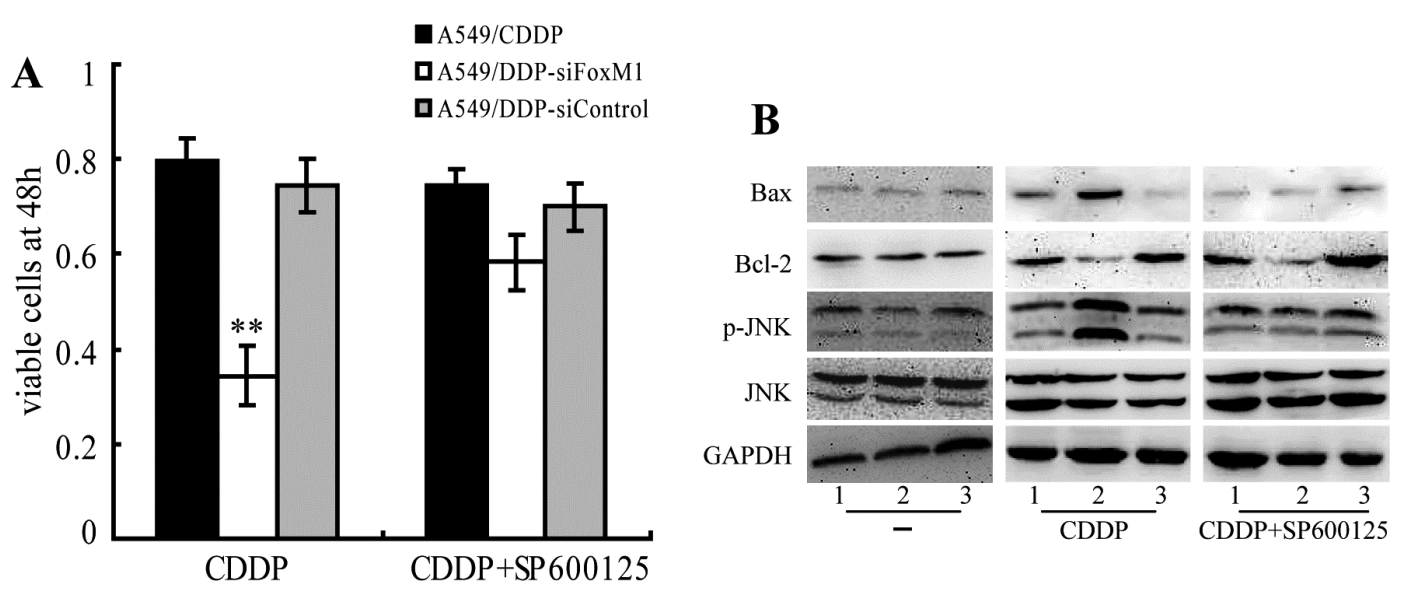

Figure 6. Analysis of the results of the A549/CDDP-siFoxM1, A549/CDDP-siControl and A549/CDDP-nontransfection cells treated with cisplatin or cisplatin plus SP600125. (A) The cell viability and apoptosis were assessed using the CCK-8. The RNAi-enhanced apoptosis of A549/CDDP cells in response to cisplatin could be reduced by the inhibition of the JNK pathway $\left.{ }^{* *} P<0.01\right)$. (B) The expression of the JNK and mitochondrial pathwayrelated proteins was assessed using western blot. A blockade of JNK could regulate the expression of Bax and Bcl-2. 1, A549/CDDP-nontransfection; 2, A549/CDDP-siFoxM1; 3, A549/CDDP-siControl. Statistical analysis was done using ANOVA analysis. 
induced A549/CDDP cell apoptosis through activation of the JNK/mitochondrial pathway. These results suggest that FoxM1 plays a critical role in chemoresistance to cisplatin and FoxM1 depletion may be a promising approach to improve lung cancer therapy.

Cisplatin is a platinum-based compound that forms intraand inter-strand adducts with DNA. These adducts distort the DNA conformation and inhibit replication and transcription, leading to the activation of multiple signaling pathways involved in the cell cycle and apoptosis [4]. Previous studies have reported that the main molecular mechanisms of chemoresistance involve the activation of cell cycle pathways, increased DNA damage repair, and alterations in apoptosis regulator genes [29]. Two major signaling pathways that lead to apoptosis have previously been described [30]. One pathway involves death receptors and tumor necrosis factor receptors (TNFRs), whereas the other pathway is the mitochondrial pathway that involves the $\mathrm{Bcl}-2$ and $\mathrm{Bax}$ proteins. $\mathrm{Bcl}-2$ is well known as an anti-apoptotic mediator, and the overexpression of $\mathrm{Bcl}-2$ can inhibit cell apoptosis that is induced by free radicals, radiation, steroid hormones, chemotherapy, and oncogenes. The proapoptotic protein Bax can promote the release of cytochrome $c$ into the cytosol from mitochondria that activates caspases that are involved in apoptosis [30].

In this study, we first observed the FoxM1 expression status in 50 unresectable stage III-IV NSCLC patients who were treated with a cisplatin-based regimen as first-line therapy. We did not find a significant relationship between the FoxM1 expression level and the histological grade or the clinical stage that represented the clinical course of the disease. This finding may be attributed to the small number of samples and the late clinical stage of these patients. For further verification, the sample size will be increased. When we analyzed the outcome, we found that FoxM1 was a negative factor that was associated with sensitivity to cisplatin and a shorter survival time. Thus, FoxM1 could be a useful marker for predicting and monitoring responses to cisplatin and prognoses in NSCLC patients.

It has been previously reported that FoxM1 is a proliferation-specific transcription factor [31]. FoxM1 promotes G1/S transition and tumor cell invasiveness through mitogenactivated protein kinases (MAPKs) [32]. MAPKs are serine/ threonine kinases that transduce signals from the cell membrane to the nucleus in response to a wide range of stimuli [33, 34]. The MAPK signaling pathways modulate gene expression, mitosis, proliferation, motility, metabolism, and programmed cell death (i.e., apoptosis) [35-37]. There are three family members of the conventional MAPKs: the extracellular signalregulated kinase (ERK), JNK, and p38-MAPK [38]. Recent evidence suggests that the activity of the Raf/MEK/MAPK is necessary and sufficient for the nuclear translocation of FoxM1 [39]. Moreover, FoxM1 has been identified downstream of Ras-MKK3-p38 in the regulation of in vitro cellular invasion [40]. JNK plays a major role in cisplatin-induced cancer cell apoptosis $[41,42]$. However, the relationship between FoxM1 and the JNK pathway in cancer resistance has not been re- ported. Wang et al. reported that FoxM1 acts as an upstream regulator of the JNK1 signaling pathway to promote the G1/S transition and tumor cell invasiveness. They demonstrated that FoxM1 directly binds and activates the JNK1 promoter [32]. Based on previous studies, we hypothesized that FoxM1 mediated sensitivity to cisplatin in A549 cells via the JNK/ mitochondrial pathway.

To test this hypothesis, we silenced FoxM1 expression in A549/CDDP cells and treated the cells using cisplatin with or without a specific inhibitor of JNK. We found that when the expression of FoxM1 was downregulated, p-JNK level was increased and accompanied by an enhanced sensitivity to cisplatin. Previous studies have verified that p-JNK expression is an indirect measure of JNK activation [43]. The balance of $\mathrm{Bcl}-2 / \mathrm{Bax}$ expression is an important mark of the apoptosis signaling pathway. The results suggested that JNK was an apoptotic signal that was activated by the silencing of FoxM1. Interestingly, the blockade of JNK with SP600125 significantly reversed the activation of the mitochondrial pathway, inhibited the cell apoptosis pathway, and the sensitivity of the A549/ CDDP-siFoxM1 cells to cisplatin was reduced. These results suggested that the JNK pathway is an essential signaling pathway that participates in the regulation of FoxM1 in cisplatin resistance. However, the mechanism of drug resistance in tumors is complicated and involves multiple signaling pathways. Therefore, multiple genes, including FoxM1, may interact with each other and form an intricate network. Remarkably, many of the target genes of FoxM1, such as p53 and polo-like kinase 1 (PLK1), are associated with multidrug resistance. Evidence suggests that ATM and p53 coordinately regulated FoxM1 to modulate responses and resistance to epirubicin in breast cancer [19]. It has been shown that PLK1 plays a role in DNA damage recognition with homologous recombination repair and has been involved in multidrug resistance [44-46]. Based on the interaction between FoxM1 and its downstream genes, FoxM1 could be used as a therapeutic target to overcome acquired resistance to chemotherapy.

This study has several limitations. First, we only focused on one cell line, A549, which is a widely used human lung adenocarcinoma cell line. Additional observations in other cell lines may strengthen the significance of our study. Second, we explored one signaling pathway, the JNK pathway, and there may be other FoxM1 target genes and pathways that are associated with multidrug resistance. However, these limitations did not influence the conclusion of our study. Third, we only investigated the JNK phosphorylation level. The mechanisms of how FoxM1 regulates the JNK pathway still remain unclear. Additional efforts will contribute to our understanding of the precise underlying mechanisms explaining how FoxM1 suppression enhances lung cancer cell sensitivity to cisplatin.

In summary, based on our experiments, FoxM1 is a critical mediator of cisplatin sensitivity in NSCLC. The downregulation of FoxM1 enhanced cisplatin-induced A549/CDDP cell apoptosis through activation of the JNK/mitochondrial pathway. Therefore, a combination of cisplatin treatment 
with FoxM1 depletion may be an effective approach to lung cancer therapy.

Acknowledgments: The work was supported by the Science Project in Jiangsu Province, Jiangsu China (Z201216). This work was supported by the priority academic program development of the Jiangsu Higher Education Institutions (PAPD, JX10231801). We thank Dr. Guoxing Song and Rong Rong for their great helps in immunohistochemical analysis. We would like to thank the editors and reviewers for their kind instructions, which will be helpful for our future studies.

\section{References}

[1] JEMAL A, SIEGEL R, WARD E, MURRAY T, XU J et al. Cancer statistics, 2007. CA Cancer J Clin 2007; 57: 43-66. http://dx.doi.org/10.3322/canjclin.57.1.43

[2] JEMAL A, MURRAY T, WARD E, SAMUELS A, TIWARI RC et al. Cancer statistics, 2005. CA Cancer J Clin 2005; 55: 10-30. http://dx.doi.org/10.3322/canjclin.55.1.10

[3] MOLINA JR, YANG P, CASSIVI SD, SCHILD SE, ADJEI AA. Non-small cell lung cancer: epidemiology, risk factors, treatment, and survivorship. Mayo Clin Proc 2008; 83: 584-594. http://dx.doi.org/10.1016/S0025-6196(11)60735-0

[4] KELLAND L. The resurgence of platinum-based cancer chemotherapy. Nat Rev Cancer 2007; 7: 573-584. http://dx.doi. org/10.1038/nrc2167

[5] STEWART DJ. Mechanisms of resistance to cisplatin and carboplatin. Crit Rev Oncol Hematol 2007; 63: 12-31. http:// dx.doi.org/10.1016/j.critrevonc.2007.02.001

[6] MADUREIRA PA, VARSHOCHI R, CONSTANTINIDOU D, FRANCIS RE, COOMBES RC et al. The Forkhead box M1 protein regulates the transcription of the estrogen receptor alpha in breast cancer cells. J Biol Chem 2006; 281: 25167-25176. http://dx.doi.org/10.1074/jbc.M603906200

[7] WIERSTRA I, ALVES J. FOXM1c and Sp1 transactivate the P1 and P2 promoters of human c-myc synergistically. Biochem Biophys Res Commun 2007; 352: 61-68. http://dx.doi. org/10.1016/j.bbrc.2006.10.151

[8] WONSEY DR, FOLLETTIE MT. Loss of the forkhead transcription factor FoxM1 causes centrosome amplification and mitotic catastrophe. Cancer Res 2005; 65: 5181-5189. http:// dx.doi.org/10.1158/0008-5472.CAN-04-4059

[9] PETROVIC V, COSTA RH, LAU LF, RAYCHAUDHURI P, TYNER AL. FoxM1 regulates growth factor-induced expression of kinase-interacting stathmin (KIS) to promote cell cycle progression. J Biol Chem 2008; 283: 453-460. http://dx.doi. org/10.1074/jbc.M705792200

[10] PARKHJ,COSTARH,LAU LF, TYNERAL, RAYCHAUDHURI P. Anaphase-promoting complex/cyclosome-CDH1-mediated proteolysis of the forkhead box M1 transcription factor is critical for regulated entry into S phase. Mol Cell Biol 2008; 28: 5162-5171. http://dx.doi.org/10.1128/MCB.00387-08

[11] LAOUKILI J, KOOISTRA MR, BRÁS A, KAUW J, KERKHOVEN RM et al. FoxM1 is required for execution of the mitotic programme and chromosome stability. Nat Cell Biol 2005; 7: 126-136. http://dx.doi.org/10.1038/ncb1217
[12] HUANG C, QIU Z, WANG L, PENG Z, JIA Z et al. A novel FoxM1-caveolin signaling pathway promotes pancreatic cancer invasion and metastasis. Cancer Res 2012; 72: 655-665. http://dx.doi.org/10.1158/0008-5472.CAN-11-3102

[13] XIA JT, WANG H, LIANG LJ, PENG BG, WU ZF et al. Overexpression of FOXM1 Is Associated With Poor Prognosis and Clinicopathologic Stage of Pancreatic Ductal Adenocarcinoma. Pancreas 2012; 41: 629-635. http://dx.doi.org/10.1097/ MPA.0b013e31823bcef2

[14] KIM IM, ACKERSON T, RAMAKRISHNA S, TRETIAKOVA M, WANG IC et al. The Forkhead Box m1 transcription factor stimulates the proliferation of tumor cells during development of lung cancer. Cancer Res 2006; 66: 2153-2161. http://dx.doi. org/10.1158/0008-5472.CAN-05-3003

[15] BEKTAS N, HAAF A, VEECK J, WILD PJ, LÜSCHERFIRZLAFF J et al. Tight correlation between expression of the Forkhead transcription factor FOXM1 and HER2 in human breast cancer. BMC Cancer 2008; 8: 42. http://dx.doi. org/10.1186/1471-2407-8-42

[16] CHU XY, ZHU ZM, CHEN LB, WANG JH, SU QS et al. FOXM1 expression correlates with tumor invasion and a poor prognosis of colorectal cancer. Acta Histochem 2012; 114: 755-762. http://dx.doi.org/10.1016/j. acthis.2012.01.002

[17] BERGAMASCHI A, CHRISTENSEN BL, KATZENELLENBOGEN BS. Reversal of endocrine resistance in breast cancer: interrelationships among 14-3-3zeta, FOXM1, and a gene signature associated with mitosis. Breast Cancer Res 2011; 13: R70. http://dx.doi.org/10.1186/bcr2913

[18] REN S, ZHOU S, ZHANG L, XU J, LV M et al. High-level mRNA of excision repair cross-complementation group 1 gene is associated with poor outcome of platinum-based doublet chemotherapy of advanced nonsmall cell lung cancer patients. Cancer Invest 2010; 28: 1078-1083. http://dx.doi. org/10.3109/07357901003735659

[19] MILLOUR J, DE OLANO N, HORIMOTO Y, MONTEIRO LJ, LANGER JK et al. ATM and 553 regulate FOXM1 expression via E2F in breast cancer epirubicin treatment and resistance. Mol Cancer Ther 2011; 10: 1046-1058. http://dx.doi. org/10.1158/1535-7163.MCT-11-0024

[20] KWOK JM, PECK B, MONTEIRO LJ, SCHWENEN HD, MILLOUR J et al. FOXM1 confers acquired cisplatin resistance in breast cancer cells. Mol Cancer Res 2010; 8: 24-34. http:// dx.doi.org/10.1158/1541-7786.MCR-09-0432

[21] MARINTCHEV A, ROBERTSON A, DIMITRIADIS EK, PRASAD R, WILSON SH et al. Domain specific interaction in the XRCC1-DNA polymerase beta complex. Nucleic Acids Res 2000; 28: 2049-2059. http://dx.doi.org/10.1093/ $\underline{\text { nar/28.10.2049 }}$

[22] KARRAN P. DNA double strand break repair in mammalian cells. Curr Opin Genet Dev 2000; 10: 144-150. http://dx.doi. org/10.1016/S0959-437X(00)00069-1

[23] TUTT A, BERTWISTLE D, VALENTINE J, GABRIEL A, SWIFT $S$ et al. Mutation in Brca2 stimulates error-prone homology-directed repair of DNA double-strand breaks occurring between repeated sequences. EMBO J 2001; 20: 4704-4716. http://dx.doi.org/10.1093/emboj/20.17.4704 
[24] YUAN SS, LEE SY, CHEN G, SONG M, TOMLINSON GE et al. BRCA2 is required for ionizing radiation-induced assembly of Rad51 complex in vivo. Cancer Res 1999; 59: 3547-3551.

[25] TAN Y, RAYCHAUDHURI P, COSTA RH. Chk2 mediates stabilization of the FoxM1 transcription factor to stimulate expression of DNA repair genes. Mol Cell Biol 2007; 27: 1007-1016. http://dx.doi.org/10.1128/MCB.01068-06

[26] PARK YY, JUNG SY, JENNINGS N, RODRIGUEZ-AGUAYO C, PENG G et al. FOXM1 mediates Dox resistance in breast cancer by enhancing DNA repair. Carcinogenesis 2012; 33: 1843-1853. http://dx.doi.org/10.1093/carcin/bgs167

[27] CARR JR, PARK HJ, WANG Z, KIEFER MM, RAYCHAUDHURI P. FoxM1 mediates resistance to herceptin and paclitaxel. Cancer Res 2010; 70: 5054-5063. http://dx.doi. org/10.1158/0008-5472.CAN-10-0545

[28] XU N, ZHANG X, WANG X, GE HY, WANG XY et al. FoxM1 mediated resistance to gefitinib in non-smallcell lung cancer cells. Acta Pharmacol Sin 2012; 33: 675-681. http://dx.doi. org/10.1038/aps.2011.188

[29] WANG G, REED E, LI QQ. Molecular basis of cellular response to cisplatin chemotherapy in non-small cell lung cancer (Review). Oncol Rep 2004; 12: 955-965.

[30] ASHKENAZI A, DIXIT VM. Death receptors: signaling and modulation. Science 1998; 281: 1305-1308. http://dx.doi. org/10.1126/science.281.5381.1305

[31] COSTA RH. FoxM1 dances with mitosis. Nat Cell Biol 2005; 7: 108-110. http://dx.doi.org/10.1038/ncb0205-108

[32] WANG IC, CHEN YJ, HUGHES DE, ACKERSON T, MAJOR ML et al. FoxM1 regulates transcription of JNK1 to promote the G1/S transition and tumor cell invasiveness. J Biol Chem 2008; 283: 20770-20778. http://dx.doi.org/10.1074/jbc. M709892200

[33] BURKE JG, RW GW, CONHYEA D, MCCORMACK D, DOWLING FE et al. Human nucleus pulposis can respond to a pro-inflammatory stimulus. Spine (Phila $\mathrm{Pa}$ 1976) 2003; 28: 2685-2693. http://dx.doi.org/10.1097/01. BRS.0000103341.45133.F3

[34] CHANG L, KARIN M. Mammalian MAP kinase signalling cascades. Nature 2001; 410: 37-40. http://dx.doi. org/10.1038/35065000

[35] FENG DY, ZHENG H, TAN Y, CHENG RX. Effect of phosphorylation of MAPK and Stat 3 and expression of c-fos and $\mathrm{c}$-jun proteins on hepatocarcinogenesis and their clinical significance. World J Gastroenterol 2001; 7: 33-36.

[36] RAGGATT LJ, EVDOKIOU A, FINDLAY DM. Sustained activation of Erk1/2 MAPK and cell growth suppression by the insert-negative, but not the insert-positive isoform of the human calcitonin receptor. J Endocrinol 2000; 167: 93-105. http://dx.doi.org/10.1677/joe.0.1670093

[37] WADA T, PENNINGER JM. Mitogen-activated protein kinases in apoptosis regulation. Oncogene 2004; 23: 2838-2849. http://dx.doi.org/10.1038/sj.onc.1207556

[38] JOHNSON GL, LAPADAT R. Mitogen-activated protein kinase pathways mediated by ERK, JNK, and p38 protein kinases. Science 2002; 298: 1911-1912. http://dx.doi. org/10.1126/science. 1072682

[39] MA RY, TONG TH, CHEUNG AM, TANG AC, LEUNG WY et al. Raf/MEK/MAPK signaling stimulates the nuclear translocation and transactivating activity of FOXM1c. J Cell Sci 2005; 118: 795-806. http://dx.doi.org/10.1242/jcs.01657

[40] BEHREN A, MÜHLEN S, ACUNA SANHUEZA GA, SCHWAGER C, PLINKERT PK et al. Phenotype-assisted transcriptome analysis identifies FOXM1 downstream from Ras-MKK3-p38 to regulate in vitro cellular invasion. Oncogene 2010; 29: 1519-1530. http://dx.doi.org/10.1038/ onc. 2009.436

[41] CHATTOPADHYAY S, MACHADO-PINILLA R, MANGUAN-GARCÍA C, BELDA-INIESTA C, MORATILLA C et al. MKP1/CL100 controls tumor growth and sensitivity to cisplatin in non-small-cell lung cancer. Oncogene 2006; 25: 3335-3345. http://dx.doi.org/10.1038/sj.onc.1209364

[42] WANG LY, TU Z. Lung tumor diagnosis and subtype discovery by gene expression profiling. Conf Proc IEEE Eng Med Biol Soc 2006; 1: 5868-5871.

[43] ULUKAYA E, PIRIANOV G, KURT MA, WOOD EJ, MEHMET H. Fenretinide induces cytochrome $c$ release, caspase 9 activation and apoptosis in the absence of mitochondrial membrane depolarisation. Cell Death Differ 2003; 10: 856859. http://dx.doi.org/10.1038/sj.cdd.4401242

[44] YATA K, LLOYD J, MASLEN S, BLEUYARD JY, SKEHEL M et al. Plk1 and CK2 act in concert to regulate Rad51 during DNA double strand break repair. Mol Cell 2012; 45: 371-383. http://dx.doi.org/10.1016/j.molcel.2011.12.028

[45] BENOIT DS, HENRY SM, SHUBIN AD, HOFFMAN AS, STAYTON PS. pH-responsive polymeric sirna carriers sensitize multidrug resistant ovarian cancer cells to doxorubicin via knockdown of polo-like kinase 1. Mol Pharm 2010; 7: 442-455. http://dx.doi.org/10.1021/mp9002255

[46] JIMENO A, RUBIO-VIQUEIRA B, RAJESHKUMAR NV, CHAN A, SOLOMON A et al. A fine-needle aspirate-based vulnerability assay identifies polo-like kinase 1 as a mediator of gemcitabine resistance in pancreatic cancer. Mol Cancer Ther 2010; 9: 311-318. http://dx.doi.org/10.1158/1535-7163. MCT-09-0693 